\title{
META-ANALYSIS OF CORRELATION BETWEEN IRON TABLET INTAKE AND LOW BIRTH WEIGHT
}

\author{
Fara Khansa Azizah, Bhisma Murti \\ Masters Program in Public Health, Universitas Sebelas Maret
}

\begin{abstract}
Background: During the course of pregnancy, as iron stores decrease, the absorption of dietary nonheme iron increases. However, the adequacy of this homeostatic response is limited by the amount of absorbable iron in the diet and the high iron requirements for pregnancy. Therefore, pregnant women need additional iron tablet during pregnancy. This study aimed to investigate correlation between iron tablet intake and low birth weight using meta-analysis.

Subjects and Method: A systematic review and meta analysis was conducted by collecting articles from PubMed, Google Scholar, and Science Direct databases. The articles were selected by the eligibility criterias, including Population= pregnant women, Intervention $=$ iron tablet, Comparison $=$ non irot tablet, and outcome $=$ low birth weight. Articles that met the criteria were analyzed by Revman $5 \cdot 3$.

Results: 8 studies were selected for meta analysis. This study found that pregnant women who did not consume iron tablet have higher risk to deliver infants with low birth weight $(\mathrm{OR}=2.66$; CI 95\%=1.38-5.14; $\mathrm{p}=0.001)$.

Conclusion: Pregnant women who do not consume iron tablet have higher risk to deliver infants with low birth weight.
\end{abstract}

Keywords: iron tablet, low birth weight, nutrional status

\section{Correspondence:}

Fara Khansa Azizah. Masters Program in Public Health, Universitas Sebelas Maret. Jl. Ir. Sutami 36A, Surakarta 57126, Central Java. Email: farakhansa96@gmail.com Mobile: 082243043940. 